ISSN: 0213-2079 - ISSN electrónico: 2386-3889

DOI: https://doi.org/10.14201/shhmo2018401159193

\title{
SILENCIO Y OBEDIENCIA EN EL PROYECTO EDUCATIVO DE LA CATALANA JULIANA MORELL (1594-1653)"
}

\section{Silence and Obedience in the Educational Project of the Catalan nun Juliana Morell (1594-1653)}

\author{
Rosa M. ${ }^{a}$ ALABRÚS IGLESIAS \\ Universitat Abat Oliba CEU (Barcelona) \\ Correo-e: ralabrusi@uao.es \\ ORCID: 0000-0001-5886-5347
}

RESUMEN: El artículo analiza la proyección como monja dominica de la catalana Juliana Morell, así como su pensamiento y discurso educativo en el marco de la ofensiva recatolizadora de la Francia de principios del siglo xviI después de la muerte de Enrique IV. A partir de la documentación de la Bibliothèque Nationale de France y de la Bibliothèque Municipale y la Bibliothèque Ceccano d'Avignon se examinan las obras y la correspondencia de este personaje que fue niña prodigio y después priora en el convento de Santa Práxedes de Aviñón. En especial se subrayan sus ideas sobre la educación, el silencio y la obediencia en el marco de la disciplina conventual. Queda bien patente la influencia del pragmatismo jesuítico (De la Puente y Rodríguez), su distanciamiento del alumbradismo y del quietismo, su reivindicación de la humildad y la mortificación y la exaltación de la unión intelectual con Dios, lejos de las experiencias sensoriales barrocas.

Palabras clave: Educación; silencio; obediencia; alumbradismo; quietismo; humildad.

* Este trabajo ha sido realizado en el marco del Proyecto de Investigación de referencia HAR2014-52434-C5-4-P, financiado por el Ministerio de Economía y Competitividad del Gobierno de España. 
ABSTRACT: This article analyzes the projection as Dominican nun of the Catalan Juliana Morell, as well as her thought, and educational discourse within the framework of the recatholizing offensive in France at the beginning of the 17th century after the death of Henry IV. From the documentation of the National Library of France and the Municipal Library and the Library Ceccano of Avignon the works and the correspondence of this personage, who was child prodigy and later prioress in the convent of Sainte-Praxède in Avignon, are examined. In particular, her ideas about education, silence, and obedience are underlined within the framework of conventual discipline. The influence of Jesuit pragmatism (De la Puente and Rodríguez), her distancing from alumbradismo and quietism, her vindication of humility and mortification, and the exaltation of the intellectual union with God, far away from Baroque sensory experiences, is clearly evident.

Key words: Education; silence; obedience; alumbradismo; quietism; humility.

La monja dominica catalana Juliana Morell, nacida en Barcelona, en 1594, y muerta en Aviñón, en 1653, es un personaje que, por su elevada formación intelectual y sus largos años de presencia en el convento de Santa Práxedes de Aviñón, ha sido estudiada por historiadores de su propia Orden religiosa, la de Predicadores, desde muy pronto. En este sentido destacan las biografías de los dominicos Esteban Tomás Souèges (1678), María de Merles de Beauchamps (1680), Pedro Baron (1680), Mateo José Rousset (1893) entre los más significativos $^{1}$. Esta historiografía defiende la manipulación de Juliana por su padre, el comerciante y financiero Juan Antonio Morell. Todos subrayan que Juliana tuvo

1. Bibliothèque Municipale-Bibliothèque Ceccano d'Avignon (BMA-BCA), $8^{\circ}$ 27153, Beauchamps, M. de M.: «Abregé de la vie de la Vénerable et heureuse mémoire de la mère Julienne Morell, vierge de l'Ordre des Frères Prêcheurs et Religieuse du Monastère de SaintePraxède de la ville d'Avignon», en La Règle de Saint Augustin traduite en français et enrichie de diverses explications et belles remarques pour servir d'instruction à toutes les personnes qui font profession de la suivre, par la R.M. Julienne Morell, religieuse de S. Dominique du Convent de Sainte-Praxède de la ville d'Avignon. Avignon, Chez Laurens Lemolt Imprimeur et Libraire de sa sainteté et de la ville, 1680, pp. 196-234; BMA-BCA, 8²7153, BARON, P.: «Biografía de Julienne Morell», en La Règle de Saint Augustin... Avignon, Chez Laurens Lemolt Imprimeur et Libraire de sa sainteté et de la ville, 1680, pp. 235-249; Bibliothèque Nationale de France (BNF), Microfiche M-13844, Rousset, M. J.: La Vénerable mère Julienne Morell, sa vie, sa doctrine, son institut. París, Lyon, Delhomme et Briquet, 1893; SouÈGEs, E. T. o. p.: «La vie de la Vénérable Mère Julienne Morell, professe du Monastère de Sainte- Praxède à Avignon», L'année dominicaine, Amiens, Chez Guislain Le Bel, vol. 6, 1678. 
una excelente educación. Apenas mencionan a la madre o bien coinciden en su temprana muerte y en que su progenitor siguió preocupándose en formarla, tras su huida de Cataluña a Francia, en 1599, por asuntos turbios². Al comienzo, la dejó al cuidado de las monjas dominicas barcelonesas de Montesión. En 1601, la hizo recoger, para llevarla consigo a Lyon, donde contrató para ella a los mejores maestros, procedentes de toda Europa.

El dominio de lenguas y la ciencia adquirida por Juliana fueron tantos que, en $1604, \tan$ solo con diez años, la adolescente tradujo la Biblia del hebreo, al griego y al latín, tal y como consta en las Precationes Aliquot celebriores e sacris Bibliis... publicada por Martin Le Jeune, librero e impresor de la Universidad de París, quien logró el privilegio exclusivo del Parlamento francés para editarla durante un período de seis años (1603-1608), así como la garantía de penalización a los demás libreros que pretendieran competir ${ }^{3}$.

El padre la instruyó a destajo. Luego, constatando las grandes capacidades de su hija y la facilidad para hablar y escribir idiomas (a los doce años sabía latín, griego, hebreo, árabe, caldeo, italiano y francés) la exhibió en público, como niña prodigio, logrando llenar los auditorios. El primer acto público orquestado por Morell padre fue en Lyon, en 1606. Asistió lo más granado de la sociedad católica en un medio notablemente marcado por la influencia hugonote entre los que se mezclaban también banqueros y prestamistas privados catalanes como los Puiggener ${ }^{4}$. El que los protestantes hugonotes no hubieron lanzado dardos contra Morell y su hija podría explicarse en el contexto de relativa tolerancia religiosa, marcada por Enrique IV, tras el Edicto de Nantes (1598). En Lyon, la vieron exponer tesis orales en filosofía, intelectuales de todas partes y de diferentes creencias (el filósofo belga André Schott, el jurista alemán Journmann, el geógrafo también alemán Abraham Goelnitz). La superdotada fue considerada el nuevo fénix del siglo ${ }^{5}$.

2. SouÈges, R. M.a: «Entre el protestantismo y el catolicismo. Conversión y espiritualidad femenina: Juliana Morell», e-Spania, Revue interdisciplinaire d'études hispaniques médiévales et modernes. París, 26 février, 2017, pp. 1-15.

3. BMA-BCA, $8^{\circ}$ 23293, Morell, J. (trad.): Precationes Aliquot celebriores e sacris Bibliis desumptae ac in studiorum gratia lingua Hebraica, Graeca $\mathcal{E}$ Latine in Enchiridis formulam redactae. París, Martinum Iuvenem, 1604.

4. Hernández, B.: «Hombres de negocios y finanzas públicas en la Cataluña de Felipe II», Revista de Historia Económica, Universidad Carlos III, Madrid, año 15, n 1, 1997.

5. Morel-Fatio, A.: «Carta de Juan Antonio Morell, dando noticias circunstanciales de su célebre hija Juliana», Revista de Archivos, bibliotecas y museos, Madrid, 1876, pp. 195-199; en los Archives Départementales de Vaucluse à Avignon (ADVA), 77H., Sainte-Praxède, Dames de Sainte-Praxède (Dominicaines) figura que fue en 1608 cuando Juliana defendió tesis en Filosofía en la Universidad de Lyon, pp. 184-185. 
Tras el acto lionés el padre la presionó para que estudiara jurisprudencia y profundizara en teología, con el objetivo de promover más actos con este perfil, prometiéndole riqueza y reputación. Un día, la joven Juliana se cansó y decidió seguir por otro camino. Ingresó, en 1609, en el monasterio de Santa Práxedes de Aviñón para profesar como monja al año siguiente.

María de Merles Beauchamps, Esteban Tomás Souèges o Mateo José Rousset... sostienen que Juan Antonio Morell se negó a aceptar la «mutación» de la hija, maltratándola en el período previo al ingreso conventual. Dramatizan cómo la desheredó y no le suministró dote para su profesión. Recientemente, la historiografía que ha tratado la trayectoria de Juliana Morell (desde el siglo xix hasta el día de hoy: Ahumada, Lamy, Levesque, Gassó y Espargaró...) reitera la misma tesis e incluso apunta que la elección del claustro pudo ser una liberación para ella ${ }^{6}$.

La violencia previa al convento, sufrida por las mujeres-monjas ha sido una variable que ha contado en muchos de los relatos de religiosas $\mathrm{y}$, a menudo, se ha convertido en pieza fundamental de los argumentos de la espiritualidad femenina por sus connotaciones épico-morales. Para el mismo período, entre muchas otras, se pueden recordar aquí los casos de Catalina de Ana de Jesús (1560-1617), Ángela Margarita Prat, más conocida como Ángela Serafina (1543-1608) o Leonor de la Misericordia (1552-1620), cuyas vidas están asociadas a maridos violentos, mientras que las de Francisca Vacchini de Viterbo (1589-1609) o la ya citada Juliana Morell a padres o madres maltratadores ${ }^{7}$.

Cuando Juliana decidió profesar en el convento de dominicas, en 1609, prácticamente, coincidió con el regicidio de Enrique IV, en 1610, por un integrista católico (Ravaillac), lo que supuso el fin de la tolerancia religiosa que regía en Francia. La oposición protestante creció en Lyon frente a la Aviñón católica. Se acentuó la polarización religiosa. Los hugonotes no estaban dispuestos a perder prebendas. Exigían, además, representación, tanto en los sínodos como en la asamblea nacional, por lo que, de nuevo, se reactivaron las guerras de religión. Por otra parte, la pérdida de la influencia española en Francia, desde 1587, se

6. Ahumada Batlle, E. de: «Juliana Morell, una humanista catalana», Institut Nova Historia, mayo, 2010, https://www.inh.cat; Lamy, T.: Child Prodigy, Religious Reformer, Spiritual Writer, Ph D, Nueva York University, 1992; LevesQue, J.-D. o. p.: «Julienne Morell», Mémoire Dominicaine. Histoire Documents. Vie Dominicaine. Courants dominicains de spiritualité, 2, París, Les Editions du Cerf, 1993, pp. 79-100; Gassó, M. y Espargaró, A.: Aventureres de la Història: els altres noms propis de la bistòria de Catalunya. Barcelona, La Esfera de los Libros, 2006.

7. Biblioteca Facultad de Teología San Vicente Ferrer de Valencia, Gavastón, J.: La Regla que profesan las beatas de la Tercera Orden de Predicadores, J. Crisóstomo Garriz, Valencia, 1621, vol. I, pp. 5-7. 
acentuó. Anteriormente, el monasterio de Santa Práxedes había estado vinculado a la corona de Aragón, tras el nombramiento por el papa de Aviñón, Clemente VII, del canónigo Pedro Frías de Tarragona, como cardenal de este cenobio en 1394. Sin embargo, perdió esta influencia a raíz del integrismo católico de Felipe II. Los protestantes entraron en La Provenza. El convento de Santa Práxedes de Aviñón fue saqueado, sus santas reliquias, de plata, desaparecieron y las monjas huyeron a otros lugares ${ }^{8}$. Al parecer, tan solo quedaron allí algunas mujeres solas, medio abandonadas por sus maridos o viudas, a cargo de una pequeña escuela de niñas.

Estos hechos inspiraron a César de Bus, a la princesa de Condé (Carlota de la Trémouille) y a la hija del barón de Monclair, Ana de Gérente de Monclair, para solicitar a Clemente VIII la reapertura del monasterio en 1596 (se había cerrado en 1587 a partir de un Breve papal) ${ }^{9}$. Desde 1594, la conversión de Enrique IV al catolicismo había favorecido cierta relajación y la reapertura del lugar. Definitivamente, Ana Gérente de Monclair, en 1599 (poco después del Edicto de Nantes), logró sacar adelante el proyecto de reforma del priorato, obteniendo la restitución de las reliquias y las joyas de plata que habían sido arrebatadas a los dominicos ${ }^{10}$.

En todo momento Enrique IV reivindicó pragmatismo respecto a las décadas anteriores, lo que no fue bien aceptado por la Compañía de Jesús. Los jesuitas fueron quienes pretendieron recatolizar a la Lyon protestante. En el empeño lograron algunas conversiones sonadas de hijos e hijas de familias hugonotas como las de Pedro Coton o María Hubert (futura novicia de Santa Práxedes). Al morir Enrique IV la inestabilidad volvió a ser evidenciable. Le sucedió Luis XIII, pero en la práctica quien tenía el poder fue la regente María de Médicis, hasta 1617, momento en que tuvo lugar el homicidio de Concino Concini, mariscal de Ancre, favorito de la regente. Nicolás de l'Hospital fue quien lo ejecutó. La madre del rey (a la que se asociaba con la matanza anterior de hugonotes en la noche de San Bartolomé, en agosto de 1572) era partidaria de la intolerancia religiosa.

Especialmente significativa fue la resistencia protestante contra el propio Luis XIII, en 1620. A su lado el monarca tuvo, como fiel lugarteniente en el proyecto recatolizador de Languedoc y Provenza, a Enrique II de Borbón-Condé.

8. BMA, HAAG, E. y E.: La France protestante ou vies des protestants qui se sont fait un nom dans l'bistoire. Depuis les premiers temps de la Réformation jusqu'à la reconnaissance du principe de la liberté des cultes par l'Assemblée Nationale. París, Bureaux de la Publication, Rue St. Dominique d'Enfer, 11, vol I, 1846; FrIeda, L.: Catalina de Médici. Una biografía. Madrid, Siglo XXI, 2005.

9. BMA-BCA, Ms. 2809, Fundación del Monasterio de Santa Práxedes de Aviñón, escrita en el trienio de la reverenda madre Ágata de Merles de Beauchamps, 1686, pp. 22-24. Ágata de Merles fue hermana de María de Merles de Beauchamps.

10. ADVA, 77H, Sainte-Praxède, Dames de Sainte-Praxède, pp. 181-183. 
Enrique II era hijo del hugonote Enrique I, príncipe de Condé, y de la católica Carlota de la Trémouille, que, al enviudar, se erigió en bastión del catolicismo tras sufrir en sus propias carnes el radicalismo protestante que la acusaba de haber sido infiel a su marido para no legitimar a sus hijos.

Los hugonotes franceses fundaron academias del tipo de la de Ginebra, abierta por Juan Calvino desde 1559, que replanteaba la educación social, con un programa teológico para la preparación de pastores protestantes con la finalidad de contrarrestar las influencias de la Universidad de París y las universidades escolásticas. Las academias de Saumur y de Montauban constituyeron un buen ejemplo de impartición de conocimiento y educación protestante, en gramática latina, lo que constituía todo un reto para el control de los jesuitas.

La reacción católica fue la de formar congregaciones de enseñanza y proyectos educativos a través de las Órdenes religiosas (jesuitas, dominicos, oratorianos, escolapios...) para evitar las «mutaciones» o «conversiones» al protestantismo y otorgando un destacado énfasis en la educación de niñas, considerando que, el día de mañana, las mujeres podían ser un potente vehículo de transmisión cultural y religioso. En este sentido, el espíritu de las ursulinas estuvo muy arraigado en Aviñón (teniendo a María Coton, la hermana del jesuita Coton, como a una gran difusora de la pedagogía católica junto con Ana de Xainctonge que igualmente gozó de la protección de la Compañía de Jesús). La educación podía ser un buen resorte para la obediencia. Hasta aproximadamente 1623, las ursulinas siguieron la Regla de la Compañía de Jesús, pero, desde entonces, dejaron la Regla de San Ignacio para pasar, progresivamente, a la Regla de San Agustín, en la medida que iban adoptando la clausura.

A partir de 1598, Ana Gérente de Monclair fue reconocida como priora de Santa Práxedes. Consiguió donaciones de Filipa de Arpajon y la primera generación de monjas que la apoyaron como Margarita d'Arpajon, Lucrecia y Margarita de Peyret, María Luisa Grians, Juana Boyssière, Luisa Pascal, Clara de Bermond, Juana Boyssière y las «convertidas», del protestantismo al catolicismo, Antonia Bouitte y la citada María Hubert (originaria de Lyon que, por influencia de Coton, renunció al calvinismo). Juliana Morell hizo profesión definitiva en 1610, de manos de la priora Monclair. En 1615 esta última pisó fuerte el acelerador reformista apoyada por el inquisidor y prior dominico Sebastián de Michaelis y el visitador apostólico, también dominico, Claudio de Belli, ambos de Aviñón ${ }^{11}$. Sin duda la llegada de Juliana, con su sabiduría, fue clave para conseguir difundir

11. BMA-BCA, Ms 2089, Fundación del Monasterio de Santa Práxedes de Aviñón..., 1686, pp. 24-29.

Ediciones Universidad de Salamanca / @o@ Stud. his., H. ${ }^{a}$ mod., 40, n. 1 (2018), pp. 159-183 
el proyecto claustral y educativo que se propusieron. Al lado de Ana Gérente de Monclair, contribuyó vivamente a difundir la pedagogía católica. La Morell contó con el apoyo incondicional del canónigo dominico Juan Claudio Deville, de la iglesia de Saint Paul de Lyon, y del arzobispo Dionisio Simón de Marquemont, de la diócesis de Lyon, que la habían oído en su vida anterior, defendiendo exposiciones orales en aquella ciudad. Aprobaron que escribiera y tradujera del latín al francés el Tratado de la Vida espiritual escrito por San Vicente Ferrer, con unas copiosas y extensas Anotaciones en cada capítulo, que constituían, en realidad, unos auténticos tratados didácticos y moralizantes. La finalidad de las mismas era dar a conocer el camino de perfección de este santo católico para las religiosas y las niñas escolarizadas del monasterio ${ }^{12}$. De entre todos los capítulos, destaca el segundo, dedicado al silencio y autocontrol de las emociones, deseos y pasiones. En él, Juliana sostenía que "quien guardaba su lengua, guardaba su alma», es decir, que del control del habla se derivaba un refuerzo espiritual del buen cristiano de cara al enemigo o contrario:

El mejor amparo con el que puedas proveer tu alma privará que los enemigos te atrapen; pero si eres desconsiderado en tus palabras, te atraparán sin ninguna duda, y cargarán tu alma tomando el botín y saqueándola, tomando todo lo que pueda hacer de bueno en ella. Hablar demasiado priva de todo bien y provecho espiritual y evacúa toda la devoción y el favor que pudiéramos tener; disipa todas las virtudes y santas costumbres, y ahuyenta fácilmente el frecuente bálsamo de cosecha interior, adquirida a través de largas meditaciones y oraciones ${ }^{13}$.

La dominica catalana defendía el principio de que hablar mucho no era bueno. Siguiendo a San Gregorio, a San Bernardo y a San Agustín, a la hora de hacerlo, debería evitarse ofender al prójimo. Bastaría con no llevar la contraria ni discutir con nadie. Era vital, según ella, premeditar antes el mensaje que se quería transmitir, y el cómo transmitirlo (dulcemente, pausadamente y en voz baja). El comunicador debía mostrar modestia y humildad y nunca verbalizar, mientras los demás expusieran sus tesis. Con voluntad empática, hacia el interlocutor, escribió

12. BMA-BCA, $8^{\circ} 20480$, Morell, J. (trad.): Traicté de la vie spirituelle par Sint Vincent Ferrier. París, Denís Moreau, 1619. Mateo José Rousset lo reeditó en 1894 y en 1895 con el título Cuvres spirituelles de la V. M. Julienne Morell/Le chemin de la perfection et dix petits traités. Los diez pequeños tratados corresponden en realidad a las Anotaciones que hizo Juliana a cada capítulo de la traducción del latín al francés del Tratado Espiritual de San Vicente Ferrer.

13. BNF, Microfiche D-84025, Rousset, M. J. (ed.): CEuvres spirituelles de la V. M. Julienne Morell/Le chemin de la perfection et dix petits traités. París, Lyon, Delhomme et Briquet, 1895, p. 35 . 
que mientras se conversara no había que mirar ni aquí ni allá, ni elevar los ojos, ni remover la boca, ni las piernas, ni los brazos, ni la cabeza, ni gesticular demasiado con las manos, con tal de no desviar la atención del receptor. ¿Quién como ella que había hablado en público tantas veces ${ }^{\text {14 }}$

Hablar poco, responder brevemente, era casi obligado para las monjas reformadas:

Que todos los hombres moderen la lengua, pero principalmente y sobre todo las vírgenes de Jesucristo, y que éstas procuren bien cuándo y en qué manera hablen; pues no es conveniente que, de una boca que deba cantar el cántico nuevo del reino del esposo celestial, salga palabra alguna que sea contraria al cantar ${ }^{15}$.

Para Juliana, la regla del silencio, sin recrearse en el habla, era el método ideal para demostrar obediencia (a la institución), entender la necesidad (en función de las tareas o cargos a desarrollar) y ejercer la caridad con el prójimo (ayudando a los demás $)^{16}$. Recurre a San Basilio para explicar las ventajas del silencio. La costumbre de no hablar -explicaba-, ayudaba, con mayor facilidad, a olvidar el pasado, así como la memoria negativa del mismo y predisponía a aprender mejor cosas nuevas y buenas:

El silencio da buen tiempo libre para aprender lo que es necesario para saber hablar bien y con todas las condiciones, o, mejor dicho, para basarse en la humildad y en las demás virtudes, teniendo las cuales no podemos dejar de ser discretos, moderados y prudentes en nuestro hablar ${ }^{17}$.

Juliana Morell, al parecer, enmudeció entre 1609 y 1610. Prescindió del habla porque quería desprenderse de todo lo banal. Para expresar sus emociones tan solo sollozaba y gemía. Siguió el criterio jesuítico mantenido por el padre Alfonso Rodríguez: «Este negocio de ganar y convertir almas es sobrenatural y se alcanza más y se hace en él con oraciones, lágrimas y gemidos, que con palabras y voces» ${ }^{18}$. No obstante, nunca fue una religiosa de arquetípico perfil melancólico. Así lo manifiesta en sus Anotaciones al Tratado mencionado. Con la omisión del habla creía contribuir a deshacerse de la riqueza material y, de ese modo, hallar una

14. Idem, pp. 46-50.

15. Idem, p. 42.

16. Idem, p. 44.

17. Idem, pp. 53-54.

18. Rodríguez, A.: Ejercicio de perfección y virtudes cristianas. Parte tercera. De varios medios para alcanzar la virtud y la perfección. Barcelona, Imprenta Pablo Riera, 1861, vol. IX, p. 47. El jesuita Rodríguez hizo una edición en Sevilla en 1609 y otra en Francia en 1623. En 1885 se publicarían todas sus obras espirituales en ocho volúmenes.




mayor perfección de espíritu. La influencia recibida de la lectura de la obra La escalera para subir al cielo de Juan Clímaco fue crucial. Clímaco tras demostrar ser un excelente guía de conciencias, recibió duras críticas de sus compañeros, diciéndole que perdía demasiado tiempo en aconsejarlos. Aquel, al enterarse, optó por dejar de hablar durante un año. Juliana pasó por una experiencia parecida y cambió radicalmente su manera de vivir, no solo no hablando, sino al entrar en el claustro. Si le preguntaban por su erudición anterior, respondía con el silencio. Poco a poco, recuperó el habla, estrictamente necesaria, para realizar las actividades que se le adjudicaron. Desde luego tuvo mucho que ver en su restablecimiento la asunción del magisterio de novicias, aunque con el acompañamiento de la escritura. Para ellas tradujo, entre 1616 y 1617, el Tratado de la Vida espiritual de San Vicente Ferrer con las Anotaciones mencionadas, escritas por ella ${ }^{19}$.

En el horizonte moral y formativo de Juliana fueron esenciales las lecturas que hizo del jesuita Luis de la Puente (Guía Espiritual, 1609), que, a su vez, tuvo como maestro y referente a Baltasar Álvarez (confesor de Teresa de Jesús), del que la Morell escribió con admiración tras haberlo leído y estudiado a partir de la obra escrita por De la Puente, en 1615, La vida del padre Baltasar Álvarez, religioso de la Compañía, donde se subrayaba la trascendencia de la oración y la mortificación como antídotos al quietismo. No mucho después De la Puente publicó De la perfección del cristiano (1616). De su Guí Espiritual se tradujeron doce ediciones al francés. La mayoría de las monjas de Santa Práxedes, compañeras de Juliana, leyeron sus tratados a comienzos del siglo XviI (un total de quince frente a seis, que, en principio, no lo habían leído ${ }^{20}$.

Mientras para De la Puente la oración mental era un coloquio interior, sin palabras, con Dios, y dependía de la memoria, el entendimiento y la voluntad, los dominicos -como Melchor Cano o Francisco de Vitoria- por el contrario, vieron en la oración mental o silenciosa un peligro hacia el alumbradismo. En particular Vitoria se decantaba por la oración vocal. Las monjas de Santa Práxedes, adiestradas por Juliana Morell, que decía escribir siempre por obediencia a su priora (Ana de Monclair), oraban en silencio y practicaban la oración mental, impregnadas del jesuitismo ignaciano ${ }^{21}$.

19. BNF, Microfiche M-13844, Rousset, M. J. (ed.), La Vénérable Mère Julienne Morell. Dominicaine, sa vie, sa doctrine, son institut. París, Lyon, Delhomme et Briguet, 1893, pp. 42-49 y p. 57 ; BNF, Microfiche D-84025, Rousset, M. J. (ed.): CEuvres spirituelles de la V. M. Julienne Morell / Le chemin de perfection..., 1895, p. 197.

20. BMA-BCA, Ms. 2089, Fundación del Monasterio de Santa Práxedes de Aviñón..., 1686, pp. $130-138$.

21. Estela-Guilemont, M.: «El silencio es útil a toda persona cristiana. Considérations sur quelques silences», en Merle, A. y Guillaume-Alonso, A. (dirs.): Les voies du silence 
Juliana tenía además, entre sus lecturas favoritas, el libro del jesuita Alfonso Rodríguez, Ejercicio de perfección y virtudes cristianas, que se publicó en francés como Practique de la perfection et des vertus chrestiennes et religieuses en 1623. El jesuita Rodríguez enfatizaba la necesidad de los ejercicios de perfección para mejorar las virtudes de las religiosas haciendo hincapié en cómo debían corregirse, dando cuenta al confesor. Ella veía en él un modelo, para transmitir a sus novicias, acerca de la importancia del libre albedrío jesuítico y la valoración del esfuerzo personal, considerando que la educación era el medio vital, por el que la persona podía encaminarse hacia la superación y perfección moral22.

No hay que dejar de tener en cuenta tampoco las influencias del pasado en el pensamiento de Juliana. Cuando la exposición oral de Lyon, en 1606, conoció al filósofo belga Andreas Schott, autor de la obra De Bono silentii religiosorum et saecularium libri II Antverpiae apud Petrum et Joannem Belleros Fratres publicada en 1619. Casi por las mismas fechas salió a la luz el Tratado espiritual de San Vicente Ferrer con los comentarios de Juliana. Schott estudió filosofía en la Universidad de Lovaina donde conoció a humanistas de la talla de Cornelio Valerius, Augier de Busbecq e Isaac Casaubon. Enseñó griego en Toledo y en Zaragoza durante la década de 1580 y se ordenó sacerdote, completando su formación en Valencia, donde llegaría a ser profesor en el Colegio de los jesuitas de Gandía, entre 1590 y 1593, hasta que Claudio Acquaviva lo fichara para impartir docencia en retórica en el Colegio de los jesuitas de Roma. Silencio, dominio de lenguas, pasión por las traducciones para difundir y enseñar, conocimiento de la Biblia y la patrística... ${ }^{23}$ sedujeron a la joven Juliana, que lo cita, varias veces, a lo largo de sus textos. Schott cultivó también el género epistolar, género que alcanzaría un importante éxito desde el siglo xvi, en toda Europa, y que la catalana Morell, igualmente, desarrollaría con esmero.

En el epistolario de Juliana se ponen de manifiesto sus tribulaciones y sus sentimientos, a menudo, neutralizados por una extremada exaltación de la humildad. Más de uno que la conoció opinó de ella que era la persona más humilde que había conocido. En la actividad epistolar, Juliana tenía precedentes. De las cartas de religiosas de finales del siglo xvi brilló el epistolario de Teresa de Jesús, aunque no fuese editado hasta 1658 por el obispo Juan de Palafox y Mendoza ${ }^{24}$.

dans l'Espagne des Habsbourg. París, PUPS, Université Paris-Sorbonne, 2013, pp. 23 -46.

22. Gabriel, F., «Silence du crâne. Hypothèse pour une théologie du silence en images», en Merle, A. y Guillaume-Alonso, A. (dirs.): Les vois du silence..., op. cit., pp. 47-66.

23. BISELlo, L.: Sotto il «manto» del silenzio. Storia e forme del tacere (secoli XVI-XVII). Florencia, Olschki, Sagge di Lettere italiane, 60, 2003.

24. EgIdo, T.: «Santa Teresa y sus cartas, historia de los sentimientos», Hispania Sacra, 
Sobre las mismas, el carmelita descalzo Jerónimo Gracián decía que «avisaban y animaban a las cosas de religión». Teresa no era retórica y le agobiaba demasiado el halago, lo que contrasta por ejemplo con las cartas de Ana de Jesús o con la espesura demostrada en las cartas de Hipólita de Rocabertí respecto a su confesor Raimundo Samsó ${ }^{25}$. En el caso de Juliana Morell, sus cartas reflejan espontanei$\mathrm{dad}^{26}$. Nos permiten ver la relación existente entre ella y su padre, así como sus expectativas respecto a las publicaciones de sus obras, la búsqueda de apoyos e, incluso, sus inquietudes literarias. Traslucen sus inseguridades, su voluntad de empatizar y conseguir consenso social, de justificar quién había sido antes, en su vida anterior, y el porqué de su «mutación» o cambio, con una gran llaneza y moderación.

De las cartas conservadas, una fue publicada por M. J. Rousset en el s. XIX y posteriormente reproducida, a finales del siglo xx, por J. D. Levesque. En ella se constatan los vínculos afectivos de la niña hacia su padre en el momento de la salida de Barcelona. En una segunda carta, conservada en el Fondo Calvet de la Biblioteca Municipal de Aviñón, reproducida también por Levesque, con fecha precisa, 17 de mayo de 1608, Juliana, preocupada, solicitaba al duque de Monteleón del Consejo de su Majestad Felipe III, que intercediera a favor de su padre, para que pudiese volver a Barcelona, restableciéndole su honor y tuviera en cuenta su enfermedad y sus 66 años ${ }^{27}$.

Una tercera carta conservada de Juliana es de 1617. Va dirigida a la reina Ana de Austria, reina de Francia y de Navarra (hija de Felipe III y Margarita de Austria),

vol. 67, 136, 2015, pp. 401-428; «Información y comunicación en el siglo xvi: las cartas de santa Teresa de Jesús», González Martínez, R. M. a, Berrocal Gonzalo, S. y Martín de la GuARDIA, R. (coords.): Estudios en homenaje al profesor Celso Almuiña Fernández: Historia, periodismo y comunicación. Valladolid, Universidad de Valladolid, 2016, pp. 79-96; Alabrús Iglesias, R. M. y García CÁrcel, R.: Teresa de Jesús. La construcción de la santidad femenina. Madrid, Cátedra, 2015, p. 206.

25. Alabrús Iglesias, R. M. ${ }^{a}$ : «Los confesores y los relatos autobiográficos de monjas en la transición del siglo Xvi al siglo xvir: Hipólita de Rocabertí y Ana Domenge» Pedralbes, vol. 37, 2017, pp. 93-112.

26. Ahumada Batlle, E. de (ed.): Epistolaris d'Hipòlita Roís de Liori i d'Estefania de Requesens (segle XVI). Valencia, Universitat de València, 2003; «La carta privada a l'època moderna: un epistolari conventual femení inèdit», Manuscrits, 29, 2011, pp. 51-64; BARANDA Leturio, N. y Marín, M. a del C.: Letras en la celda. Cultura escrita de los conventos femeninos en la España Moderna. Madrid, Ed. Iberoamericana-Vervuert, 2014.

27. "Carta de Juliana Morell a su padre, Juan Antonio Morell», en Rousset, M. J. o. p. (ed.): La Vénérable Julianne Morell, Dominicaine, sa vie, sa doctrine, son Institut. París, Lyon, Delhomme et Briguet, 1893, p. 4; Levesque, J.-D. o. p.: «Julienne Morell...», 1993, pp. 80-83; BMA, CEuvres d'Esprit Calvet, n 2344-2349, Copia realizada por el abad Corenson de la carta escrita de Juliana Morell a su padre, vol. VI, p. 137. 
casada con Luis XIII. Narró de su propio puño y letra, a Ana, su experiencia personal del pasado y cómo, con tan solo doce años, fue capaz de defender tesis en filosofía, oralmente, en público, en Lyon. Ello le sirvió de excusa para que la reina pudiese conocer sus virtudes intelectuales:

Bien me atrevo a ofrecer a Su Majestad este pequeño presente, a falta de más humilde reconocimiento, y también añadir que, habiendo dedicado mis tesis en Filosofía, que sostuve en Lyon, y que fueron los primeros pasos de mis estudios, a la Sagrada y Real Majestad la difunta Señora, vuestra Madre de muy feliz memoria, me parecía razonable presentar a alguien más el primero de aquellos, aunque insípido y marchito, a su Majestad, que es la viva imagen de sus virtudes ${ }^{28}$.

En la carta describía su propia trayectoria y se distanciaba del maltrato doméstico. En realidad, no pretendía ni criticar ni defender a su progenitor, sino exponer, por escrito, que había finalizado la traducción del latín al francés del Tratado espiritual de San Vicente Ferrer, con el objetivo de dar a conocer con las Anotaciones o comentarios la explicación de la Sagrada Escritura, del Nuevo Testamento, de los padres de la Iglesia. No hay que olvidar que dos siglos antes, en 1416, Vicente Ferrer (canonizado en 1455), en Perpiñán, se comprometía a la obediencia a la Iglesia romana, dejando de lado al papa de Aviñón. Juliana, en el marco de la escisión entre protestantes y católicos, se erigió como recatolizadora en Provenza, reeditando el ejemplo del santo. La reedición del Tratado de aquel, conjugando teología y apostolado, obedecía a un deseo ardiente de perfección, austeridad y de poner fin a la escisión de la cristiandad ${ }^{29}$.

Relataba a la reina que era barcelonesa y las razones por las que su padre tuvo que marcharse de Cataluña a finales del siglo xvi:

Barcelona, una de las principales ciudades del Reino de Aragón, es el lugar de mi nacimiento; allí donde, no habiendo todavía alcanzado la edad de cinco años, mi padre me empezó a vincular con el estudio de las buenas letras, y con el deseo que tenía de hacerme avanzar en ellas, le ocurrió una desgracia de alguna falsa acusación, que le obligó a abandonar su país y retirarse a Francia ${ }^{30}$.

28. BMA-BCA, 8²0480, Morell, J., Traité de la vie spirituelle par Saint Vincent Ferrier. París, Denis Moreau, 1619.

29. Ibidem; Levesque, J.-D. o. p.: «Julienne Morell...», 1993, p. 85; EsponerA, A.: «San Vicente Ferrer y la misericordia», Vida sobrenatural: revista de teología mística, año 96, n. ${ }^{\circ}$ 706, 2016, pp. 267-270; «Reflexiones de san Vicente Ferrer sobre la vida religiosa a las monjas dominicas de Estavayer-Le-Lac (Suiza) en 1404», Teología espiritual, vol. 51, n. ${ }^{\circ}$ 151, 2007, pp. 103-117.

30. Levesque, J.-D. o. p., op. cit., p. 84. 
A diferencia de lo que hayan podido escribir sus biógrafos, defiende que su padre era un buen cristiano y que, al pagarle tan buenos estudios de filosofía y religión, la predispuso ya, siendo moza, hacia la espiritualidad. Añade el hecho de que no es que su padre se opusiera a que ella fuese monja, sino que incluso lo aceptaba. La condición era que ella volviese a Barcelona y entrase en un convento catalán o bien de mayor rango y reforma ya consolidada, lo que no poseía todavía, para él, Santa Práxedes de Aviñón en 1609.

Finalizaba su escrito, despidiéndose de la reina, con copiosa humildad pero, a su vez, con un vivo deseo para que se le concediera licencia real para la publicación de la traducción del Tratado de San Vicente Ferrer (del latín al francés) con las Anotaciones. Lo cierto es que Juliana logró su propósito. Entró en Santa Práxedes, ejerció, posteriormente, como maestra de novicias y reformadora y logró el ansiado permiso, nada más y nada menos que de Luis XIII, para su publicación, el 5 de abril de 1619. La licencia real otorgaba la exclusiva -por espacio de seis años-al mercader y librero de París, Denis Moreau y la prohibición de que la obra fuese vendida o distribuida durante todo este tiempo por otros impresores o libreros.

Cuando la Morell escribió la carta a la reina, en todo momento mantuvo la versión de que obedecía a la priora del monasterio (Anne de Gèrente de Monclair) y al visitador apostólico y autoridad inquisitorial Claudio de Belli:

Pues ocurrió que algunos devotos y sabios personajes, que tienen autoridad sobre nosotros, nombraron al Reverendo Padre de Belli, Vice-Inquisidor de la Fe; el cual tiene jurisdicción particular sobre nuestra casa, y habiendo sabido aquello y viendo este pequeño Opúsculo, juzgaron que era conveniente sacarlo a la luz ${ }^{31}$.

Casi diez años a posteriori de la edición del Tratado de San Vicente Ferrer el arzobispo Marius Philonardis de Aviñón decidió realizar, en 1628, un interrogatorio a todas las monjas del monasterio de Santa Práxedes. El motivo no fue encontrar heterodoxias en la traducción efectuada por la monja barcelonesa, sino porque se pretendía constatar si la reforma claustral se había impuesto con la clausura y si las monjas de Santa Práxedes se avenían a las directrices tridentinas: si habían profesado a la edad requerida por la nueva normativa exigida -dieciséis años-; que ninguna de ellas saliese de su monasterio después de haber efectuado la profesión; que la elección de cargos se hiciese correctamente; que no hubiese vocaciones forzadas y reafirmar el capítulo VIII del Concilio de Trento, sobre los fundamentos del gobierno y obediencia del monasterio, recordando a estas religiosas de Aviñón la elevada jurisdicción que tenía sobre ellas la diócesis en

31. BMA-BCA, 8²0480, Morell, J., Prólogo, Traité de la vie spirituelle..., 1619. 
detrimento de la Orden de Predicadores. Además, Philonardis apuntó deseos fiscalizadores sobre el convento, exigiendo qué dotes y rentas tenían las religiosas ante la coyuntura extrema de peste y miseria que vivió Aviñón en estas fechas y de cuyo contagio se había inculpado a los hugonotes ${ }^{32}$.

En la Biblioteca Municipal (sección de la Biblioteca Ceccano) de Aviñón se conservan tres de los cuestionarios hechos por Philonardis a las religiosas dominicas Susana Valfenière de Roger (8 de marzo de 1628), Ana Gérente de Monclair (9 de marzo de 1628) y Juliana Morell (10 de marzo de 1628). El resto de los interrogatorios realizados al resto de sus compañeras se conserva en La Minerva (de la Orden de Predicadores) en Roma. Se sabe que, del total de integrantes de la comunidad, cinco tenían entre cincuenta y sesenta años (Clara de Bermond, Maria Hubert, Catalina de Sevres, Ana Gérente de Monclair y Susana de Valfenière Rogers); cuatro eran cuarentonas (Ana de Croisset, Catalina de Julienne, Felicia de Ventabrón y Ana de Bermond); cinco estaban en la treintena (Juliana Morell, Ana Valus, Gabriela Vallat, Luisa Gaymare y Juana Grangier) y solo eran ocho veinteañeras.

La priora de aquel momento, Susana Valfenière de Roger, de 57 años, siguió las directrices reformistas de la priora anterior, Ana Gérente de Monclair. Susana, elegida en 1622 y reelegida en 1627, era natural de Aviñón, de padres conocidos (Miguel Antonio de la Valfenière y Maria Juana de Ferrier). Llevaba veintisiete años en Santa Práxedes. Respondió que nunca fue forzada a profesar en contra de su propia voluntad. Cuando Philonardis le preguntó por la edad de profesión, contestó, escuetamente: «A los catorce años». El interlocutor continuó indagando acerca de la Regla que profesaba. Ella dijo que seguía dos: la de la Observancia de Santo Domingo y la Regla de San Agustín y que las cumplía con obediencia, estudiándolas todas las noches para no olvidarlas. Quiso dejar constancia, ante Philonardis, de que leía la Guía espiritual del jesuita Luis de la Puente y el Ejercicio de perfección y virtudes cristianas del también jesuita Alfonso Rodríguez, lo que tranquilizó al arzobispo ${ }^{33}$.

En segundo lugar, la entrevistada fue Ana Gérente de Monclair. Hija de nobles (Luis Gérente, barón de Monclair, y Catalina de Trans) tenía entonces 62 años, de los que llevaba unos cincuenta en el monasterio. Era la que más conocía la historia

32. Ferrières, M.: «La peste, le juif et le protestant (Avignon 1628-1630)», en Audisio, G., Betrand, R., Ferrières, M. y otros (dirs.): Identités juives et chrétiennes. Provence, Presses Universitaires de Provence, pp. 167-177. En el estudio se apela a la malicia hugonota que como modus operandi infiltró la grasa contagiada de peste para infectar a la población de Aviñón.

33. BMA-BCA, Ms. 2089, Questionnaire adressé par l'archevêque Marius Philonardis avec les réponses données par les religieuses de Sainte-Praxède et Julienne Morell. Aviñón, 1628, p. 30 y pp. $130-132$. 
del mismo. Corroboró que, en sus prioratos, había contado con los apoyos tanto de la jerarquía eclesiástica de Aviñón como del papa y tanto de jesuitas como de dominicos. Reconoció que muchos de los confesores de sus monjas eran padres de la Compañía, pues se acogió a las directrices mandadas por el obispado de Aviñón al respeto. La dependencia hacia la diócesis de Aviñón fue enorme, a raíz del permiso papal, en 1599, de reabrir Santa Práxedes con el compromiso de reformarlo. Ello explicaría cómo la priora Ana de Gérente permitió que la mayoría de los confesores fuesen jesuitas. Si bien recibían, periódicamente, a los visitadores apostólicos dominicos que las examinaban. Ana declaró que su lectura fundamental era la Guía espiritual de Luis de la Puente, además de Jean Gerson y la vida de Santa Genoveva entre otros ${ }^{34}$.

La tercera interrogada fue Juliana Morell. Alegó que en aquel momento tenía 34 años y que era natural de Barcelona (su padre fue Antonio Morell y su madre Juana Morell). De su madre afirmó que «apenas se acordaba». Evitó profundizar en el tema pues sus padres no estaban casados. Hace referencia a que su madre murió pronto, siendo ella muy pequeña y que su padre la llevó consigo a Lyon, donde prosiguió estudios en lenguas y filosofía. Parca en palabras, ratificó que entró en el monasterio de Aviñón por voluntad propia. Asintió en que no fue forzada por su padre a profesar. Reconoce que, para ello, la ayudaron el obispo de entonces Esteban Dulcis y la princesa de Condé (Carlota de la Trémouille) a partir de la «mutación» que hizo, por obediencia a Dios.

A la pregunta sobre la Regla que profesaba, contestó sin vacilaciones: seguía a San Agustín, como era habitual en los centros educativos de niñas en Aviñón; si bien seguía igualmente las Constituciones de Santo Domingo afirmando: «No tengo otra voluntad que seguirlas». Juliana, que era la más joven de las tres y que en aquel momento todavía no había ejercido como priora, fue la que hizo mayor gala de humildad y casi no habló, pues «por mi fragilidad es extrema y mísera y cometo muchas imperfecciones».

Cuando la jerarquía la interrogó sobre si sabía leer y escribir respondió que sí, aunque reconoció que no cantaba tan bien como las otras religiosas del convento. Por lo que respecta al tipo de actividades desarrolladas en el monasterio, aseguró que la obediencia era la única que más tiempo le ocupaba, además de haber desempeñado trabajo en la despensa unos meses; algún tiempo había ejercido como guía espiritual; otro, como cantante en el coro; otros tres o cuatro años como maestra de novicias conversas -antiguas protestantes-; seis o siete como

34. Idem, p. 133. 
correctora y bibliotecaria... Garantizó al arzobispo que ella se acoplaba a todo, con tal de obedecer a Dios.

Finalmente, Philonardis preguntó a las tres por la dote aportada al convento, si tenían rentas personales y si habían hecho algún tipo de testamento o última voluntad. La priora Susana de Valfenière informó al representante de la diócesis que aportó 400 escudos en 1602, como dote, y 14 escudos de pensión anual con el hábito, muebles para su celda, etc. Declaró que estas cantidades fueron voluntarias y que no se las habían exigido para entrar en el monasterio. Sobre los derechos de sucesión defendió que todo lo dejó en herencia a su madre.

La ex priora Monclair dijo haber tenido una dote de 120 escudos en 1583. Consciente de que era poca cantidad, añadió: «En esta época las jóvenes no aportaban gran cosa». Ante el ímpetu de Philonardis sobre cómo y cuándo había profesado argumentó: «Estuve cinco años como novicia y algunos meses, pues no tenía edad suficiente todavía para profesar» y «cuando cumplí los doce años, mis padres me concedieron una pensión de 35 libras de por vida, aunque desde que se fueron de la Provenza, por las guerras de religión, dejaron de pagarla» ${ }^{35}$. Soslayó que los derechos de sucesión los había dejado a su hermano ya antes de profesar como religiosa.

Juliana Morell hace referencia a que la dote aportada en 1610 (unos 300 escudos) fue fruto de la caridad obtenida del papa Paulo V y otros personajes ilustres de Aviñón, entre ellos del cardenal de la Joyeuse que le otorgó 50 libras de por vida. Insiste que cuando su padre Juan Antonio Morell constató la perseverancia en la decisión de ella, en relación a su vocación religiosa, le fue enviando dinero. Una vez le hizo llegar 50 escudos; otra 60 así como provisiones para el monasterio. En definitiva, mantuvo ante Philonardis que calculaba que le envió unos 100 escudos, a lo largo del tiempo, aparte de cuadros, tapicería, muebles, maderas para la reconstrucción del monasterio u obras de caridad y que, tras su muerte, aquel le legó unos 400 escudos, pero que todavía no los había cobrado, ni tampoco el monasterio. Cuando le pregunta a Juliana sobre su testamento, respondió de forma contundente: «que no había cedido nada a nadie y que había tomado el hábito» ${ }^{36}$.

Es significativo que las tres mujeres contestaran lo mismo acerca de las herencias que tenían. Lo cierto es que estaban poco dispuestas a someterse a la fiscalización de Philonardis. Todas respondieron lo imprescindible, aleccionadas entre ellas. Juliana en su Anotación al capítulo segundo del Tratado a San Vicente Ferrer ya

35. Idem, pp. 134-136.

36. Ibidem. 
ROSA M. ${ }^{a}$ ALABRÚS IGLESIAS

SILENCIO Y OBEDIENCIA EN EL PROYECTO EDUCATIVO DE LA CATALANA JULIANA MORELL (1594-1653)

había previsto qué actitud debía mostrar una monja ante un interrogatorio de este calado:

El primer consejo, es pues no decir nada cuando nos interroguen; de conformidad con el parecer del Sabio: Él habla a los jóvenes en particular, a los que aconseja de manera extrema callarse: Habla, dice, apenas sobre lo que conviene a tus propios asuntos cuando sea necesario; si se le interroga dos veces, que tu cabeza responda ante todo. La versión griega utiliza otra manera, muy apta para declarar la brevedad con la que debemos hablar, y responder a los que nos interrogan (...): Reduce la respuesta a un breve sumario, diciendo pocas palabras, de manera que comprendan todo lo que quieras decir. Acorta tu discurso: ahorrando tanto tus palabras como si alguna fuera algún escudo, y haciéndolas salir de tu boca con tanta dificultad, dice San Buenaventura, como el avaricioso hace salir el dinero de su bolsa. Siguiendo pues lo dicho, cuando nos veamos obligados a hablar, que sea sucinta y brevemente, no yendo a buscar largos discursos con lo que se pueda decir con pocas palabras. Esta reserva, siendo necesaria a cada uno, lo es tanto más a las mujeres, y especialmente a las vírgenes consagradas a Dios; pues sus palabras, deberían ser tan preciosas como raras y debieran ser modestas y tan contenidas en su lengua, que nunca hablaran sin gran necesidad.

\section{Juliana continúa haciendo alusión a San Bernardo:}

Que todo hombre modere su lengua, pero principalmente y sobre todo las vírgenes de Jesucristo y que miren bien cuando y de qué manera hablan; pues no es conveniente que de una boca que deba cantar un nuevo cántico en el reino del esposo celeste, salga alguna palabra que sea contraria al cantar ${ }^{37}$.

El primer priorato de Juliana Morell (1636-1639) en Santa Práxedes, cubre buena parte de la siguiente década, en pleno contexto de la guerra de los 30 años. Amplió el coro y trasladó buena parte de las oficinas del monasterio en la planta baja; los dormitorios de las monjas, arriba. Hizo separar las monjas de las novicias y a su vez de las jóvenes internas, hijas de la nobleza o de familias católicas que las enviaban al monasterio para educarse. Igualmente ordenó que las novicias no se desprendieran de su maestra:

Tan sabia como era la venerable Juliana, encontró muchas cosas en la glosa de nuestras Constituciones en latín, que hizo observar. Una de las principales era que las novicias estuvieran completamente separadas de las reverendas, en un dormi-

37. BNF, Microfiche D-84025, Rousset, M. J. (ed.): Oeuvres spirituelles de la V.M. Julienne Morell/ Le chemin de perfection..., 1895, pp. 41-42.




ROSA M. ${ }^{a}$ ALABRÚS IGLESIAS

SILENCIO Y OBEDIENCIA EN EL PROYECTO EDUCATIVO DE LA CATALANA JULIANA MORELL (1594-1653)

torio particular con su superiora, durante los seis años en los que residieran en el noviciado ${ }^{38}$.

Y que las internas:

Estuvieran también separadas en una zona del Monasterio y que ninguna reverenda entrara en ella, más que las superioras, que deberían ser dos, con el fin de que no las dejaran nunca solas, y que dichas hijas fueran prudentes por ser reverendas y que fuera ésta la intención de sus padres ${ }^{39}$.

Aunque Juliana sostenía que muchas seguían entrando a la fuerza en el convento y que no querían ser monjas. Tal vez, esperaban recibir solo educación, además de buenas costumbres, por lo que el no separarlas de las novicias era «exponer a estas a abandonar su buen interés y voluntad».

Durante el segundo priorato de Juliana (1642-1645), se finalizó el traslado de las oficinas a la planta baja y se reconstruyó el claustro. La centralización de la administración fue total pues la priora no quería que sus monjas perdieran el tiempo yendo de habitación en habitación o haciendo pasillos.

En su tercer priorato, iniciado en 1648, logró establecer perfectamente la Observancia de las Constituciones de Santo Domingo, la clausura y la Regla de San Agustín, al unísono, con un silencio perpetuo:

Queriendo hacer una breve descripción del estado de este monasterio sobre la Observancia de las Reglas y Constituciones, tratamos de hacerlas guardar lo más perfectamente que nos sea posible, de la misma forma en que están escritas, con tal de observar la medianoche, los ayunos, la abstinencia, el uso de la lengua, con todas las otras prácticas de nuestra Orden, el guardar silencio profundo en el tiempo, en las horas y lugares ordenados por las Constituciones, así como el perpetuo silencio, de manera que nunca se hable sin un permiso especial y expreso de la superiora ${ }^{40}$.

A pesar de que su padre ya había fallecido, en sus tres prioratos, el monasterio siguió recibiendo donaciones de amigos. Ella, por su parte, continuó buscando apoyos, dentro y fuera de la Provenza, para la causa católica. En 1636, escribió a la dama italiana Constance Magalotti, casada con Karel Barberini Hertogran Monterotondo, una de las familias católicas más influyentes de La Toscana. Juliana se dirigió a ella al inicio de su primer mandato en Santa Práxedes informándola del

38. BMA-BCA, Ms 2098, Fundación del Monasterio de Santa Práxedes de Aviñón..., 1686, p. 31; ADVA, 77H, Sainte-Praxède, Dames de Sainte-Praxède, p. 186.

39. BMA-BCA, Ms 2098, Fundación del Monasterio de Santa Práxedes de Aviñón..., 1686, p. 32.

40. Idem, p. 35. 
libro que estaba escribiendo titulado Les Exercices de l'Eternité. Lo acababa de escribir, con el objetivo de que no solo sus monjas sino la sociedad, en general, de la época, lo pudiera leer, para preservar el eterno amor a Dios frente a los cambios o «mutaciones», en el marco del conflicto bélico de los treinta años entre protestantes y católicos. En el prólogo del borrador del libro, Juliana sostenía que no se trataba de ganar o perder dominios, posesiones, territorios... sino de querer eternamente a Dios. La priora escribe a la ilustre dama en un tono extremadamente modesto y cortés, al igual que en todas sus cartas. Frente a una sociedad «cambiante», en relación a cuáles debían ser las virtudes cristianas, Constance representó, para la dominica catalana, la mujer fuerte en virtudes y buenas costumbres católicas:

Me reafirmo en que no será sin la admiración de muchos que tomaré la firme decisión de dedicar esta pequeña obra a Vuestra Excelencia, puesto que nunca he tenido el honor de su conocimiento en particular, y que la gran distancia de los lugares no priva de la felicidad de su presencia. Pero esta admiración se reafirmará si se consideran vuestras virtudes, las cuales se percibirán en los siglos futuros, sosteniendo, como hacen, su esplendor por toda la Cristiandad; y que no me desconocerán, puesto que todos me admiran; ni me encontrarán ausente, puesto que a todos me comunico; ni común en todo lo que hay de riquezas tan perfectas, en relación con el asunto que he tratado; y por ello, se verá claramente que Los Ejercicios de Eternidad no podían ir mejor dedicados a aquella de la cual el nombre y la vida no son más que reflejos de la Eternidad: A la cual nada nos hace más vecinos y parecidos a la virtud excelente de la constancia, que no es otra cosa que una firme estabilidad en relación con el bien que uno ha tomado: y el cual, según San Buenaventura, mantiene el alma tan unida y junto a Dios, que nada puede inducirla a ofensa, ni apartarla de la vista de lo que es agradable a los ojos de su Majestad. ¿No es pues ser inmutable en los cambios de esta vida, el imitar ya en el tiempo a la feliz Eternidad? Y en esto mismo lo que vuestra vida representa todavía más vivamente: ver en nuestro tiempo otra Hermana María del gran Pastor Moisés, y conductora del pueblo de Dios: una segunda Ana perseverando en soledad, en ayunos y en oraciones, hasta otra santa Helena de Roma, madre de un Emperador. Madre de tres grandes príncipes, dos de los cuales dan tanto brillo a su pueblo, cuanto reciben de ella, y los tres cuanto potentes columnas sostienen, con el muy augusto, muy feliz y muy soberano Pontífice, el muy grande y santo Papa Urbano, su tío, y este bello y floreciente Imperio de la Iglesia; la cual se alimenta de los Ejercicios de piedad, y que no se contenta sino con buscarla, honrarla y abrazar la saludable cruz. En fin, una mujer fuerte el valor de la cual está en el premio, y que ha abrazado las acciones de las virtudes heroicas, no aplicando sus manos sino a las obras fuertes, piadosas y magníficas: por lo cual no cesa de servir de nuevo al corazón de su Esposo celestial, al que se encomienda y suavemente descansa en él. Encuentra tanto gusto en este mensaje del Cielo, y en este tránsito divino, que ella ha preservado en él, y en él quiere perseverar constantemente: así como la lámpara ardiente en su caridad no se apaga 
jamás, así las acciones de esta eminente virtud la alaban, en su salida de este mundo a las puertas de la Eternidad enteramente feliz de ser recibida en aquélla, con el aplauso universal de esta citada santidad. Es esto, Señora, lo que os deseo, después de una larga y feliz vida con toda la amplitud de mis afectos, y es aún lo que deseo obtener por las fervientes plegarias de vuestra Excelencia: a la cual suplico de buen corazón añadáis este pequeño presente y lo miréis con buenos ojos (aunque vuestra piedad, toda ella virtud, no tenga ninguna necesidad de ello), al que bajo el abrigo de vuestro nombre y bajo la sombra de vuestra protección (...), toda ella dedicada al servicio vuestro, de aquella que es humildemente ${ }^{41}$.

Gracias a la protección conseguida de Constance Magalotti y los Barberini, la obra se publicó en $1637^{42}$. En el prefacio del libro Juliana distribuía el tiempo que debían dedicar, desde entonces, las religiosas de Santa Práxedes tanto a la oración como a la meditación, además del programa intenso de quehaceres diarios que les establecía. Juliana quería regular el silencio y evitar el quietismo. Para ello sugería a las monjas que iban a profesar, la lectura de los Exercices de l'Eternité, tres veces al día. En ellos aconsejaba una meditación preparatoria para el retiro; una reflexión para amar a Dios eternamente (desde la creación, redención y pasión), sobre la vocación religiosa, las tentaciones, el pecado, el infierno, el paraíso, la temporalidad de la vida cristiana, el cielo, la humildad, la observancia, la paciencia, la pureza de corazón, la obediencia y la necesidad de renuncia de nosotros mismos y la anulación del deseo, acompañados de la mortificación. Con la anulación de la voluntad y de las pasiones se conseguiría la obediencia y llegar a «la maison de Dieu» y «la porte du ciel». Representaban para ella «la obediencia de Jesús crucificado es la que consiguió abrir la puerta del paraíso, cerrado por la desobediencia de Adán».

Paralelamente exhortaba el ascetismo de San Jerónimo y una radical apología de la pobreza a la que consideraba vital para la edificación espiritual, siguiendo a San Agustín. Con Les Exercices... Juliana pretendió encontrar un muro de contención frente al alumbradismo y avanzarse en la prevención del quietismo de Miguel de Molinos.

Para Juliana había que preparar el alma para que se mantuviera pura y sin pecado para lograr la perfección, pero, a diferencia, de los alumbrados o del posterior molinosismo, en este camino o proceso la meditación y la mortifica-

41. BMA-BCA, $8^{\circ}$ 20480, Morell, J. M.: "Carta a Constance Magalotti», en Exercices Spirituels sur l'éternité, avec quelques autres méditations de divers sujets et un petit Exercice préparatoire pour la Sainte Profession. Aviñón, Imprimeur de Jean Piot, Imprimeur du S. Office, 1637, pp. 2-5.

42. El dominico Mateo José Rousset reeditó los Exercices Spirituels sur l'éternité... escritos y publicados por Juliana Morell en 1637, en 1894 y 1895, como CEuvres spirituelles de la V.M. Julienne Morell, conjuntamente, con Le chemin de la Perfection et dix petit traités. 
ción debían estar siempre presentes. Su mundo nunca fue proclive a las visiones o arrobamientos tan propios de la época. La visión, en cambio, de la unión con Dios de Juliana Morell era mucho más intelectual que sensorial:

Queriendo hacer una breve descripción. La obediencia es la puerta para entrar en el cielo del corazón de mi dulce y amado Señor: en esta vida, por la gracia y una íntima unión de amor y, en la otra, por el amor consumado y glorificado ${ }^{43}$.

Juliana pudo acabar sus Exercices de l'Eternité... en su tercer priorato. Exigió el estudio del mismo por sus monjas para evaluarlas cada cierto tiempo. En el texto se nota un incremento de la valoración por parte de la superiora de la Regla de San Agustín, lo que fue algo generalizado en los demás centros educativos femeninos de Aviñón ${ }^{44}$.

De las sucesoras de la Morell y de la Monclair destacan Gabriela Vallat y su labor como fundadora de varios monasterios (en Dijon, Puy y Saint Maxim) con el fin de reformar Languedoc y Provenza tras la libertad de cultos decretada en la Paz de Westfalia (1648) y Juana de Court, novicia que estado al lado de Juliana, con frecuentes arrobos y visiones. Tras la muerte de su maestra llegó a ser priora, moderándose en su mística contemplativa, dejando el quietismo y adoptando, con obediencia, el camino del silencio de Juliana, gracias a los Exercices de l'Eternitét ${ }^{4}$. María de Merles de Beauchamps fue la nueva priora en 1678. Editó, al cabo de dos años, la Regla de San Agustín que, según ella, le había entregado la madre Juliana Morell que se le había aparecido, estando ella medio dormida. En la introducción al libro de la Regla de San Agustín justifica que la madre Juliana se la dio para que la pusiera en su habitación y la enseñara a todas las monjas de Santa Práxedes.

Según María de Merles la Regla de San Agustín tenía unos Comentarios escritos por Juliana. Llevaba la idea de publicarlos, de forma parecida a como lo hizo con las Anotaciones al Tratado de San Vicente Ferrer, pero no pudo. La muerte le sobrevino. De ahí el esfuerzo de María de Merles, en testimonio de obediencia a Juliana, logrando editarlos, con la licencia de los inquisidores y teólogos de Aviñón en $1680^{46}$.

43. BNF, Microfiche D-84025, Rousset, M. J. (ed.): CEuvres spirituelles de la V.M. Julienne Morell/ Le chemin de la Perfection et dix petit traités, $2 .^{a}$ ed., Lyon, Paris, Delhomme et Briguet, 1895, p. 282.

44. BMA-BCA, Ms. 2089, Fundación del Monasterio de Santa Práxedes de Aviñón, p. 36.

45. Idem, p. 41 y $45-46$.

46. BMA-BCA, $8^{\circ} 27$ 153, BeAuchamps, M. de M. (ed.): La Règle de Saint Augustin traduite en français et enrichie de diverses explications et belles remarques pour servir d'instruction à toutes les personnes qui font profession de la suivre, par la R.M. Julienne Morell, religieuse de S. Dominique du Convent de Sainte-Praxède de la ville d'Avignon. Aviñón, Chez Laurens

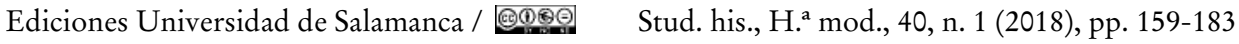




\section{Reflexiones finAles}

Juliana Morell fue una dominica singular que siguió siempre sus propios criterios no siempre coincidentes con los de su Orden de los dominicos. Silencio y obediencia son los principios fundamentales que rigen el pensamiento de Juliana. La reivindicación del silencio en el tiempo que vivió esta monja catalana suponía un viraje radical respecto a la reivindicación de la confesión pública y la oración vocal que habían sostenido los dominicos frente a las manifestaciones del alumbradismo. Entre la opción de la contemplación iluminista con toda su retórica visionaria y la exigencia de la explicación racionalista se impuso la alternativa de la prudencia jesuítica que defendió la utilidad del silencio. Se seguían así las directrices de la bona taciturnitas de Hernando de Talavera, la lucha contra el murmurar o maldecir, institucionalizando el silencio como regla en el marco de la obediencia conventual. El silencio de Juliana Morell es ante todo oral. Ella nunca dejó de escribir, aunque desarrollando más su capacidad para la traducción que la tentación de pensar sola, por ella misma. El silencio, para Juliana Morell, después de una formación tan acelerada e intensa como la que su padre le impuso fue la respuesta tacitista y prudente que en el convento postuló siempre. La obediencia conventual primaba sobre cualquier ejercicio de egoísmo espiritual. Después de tantos años infantiles de exhibición pública de sus saberes esta monja optó por la extrema discreción y el silencio obediente como fórmulas ideales para superar viejas ostentaciones.

A lo largo de sus prioratos, Juliana fue acercándose al jansenismo que había triunfado en Francia desde la publicación del Augustinus por Jansenio (1640). Nuestra monja fue extremadamente seguidora de San Agustín en su última etapa y partidaria de un rigorismo moral, de una unión intelectual con Dios, lejos de arrebatos sensoriales, y de la defensa de la delectatio coelestis, el placer en el bien.

\section{REFERENCIAS BIBLIOgRÁficAS}

Alabrús Iglesias, R. M. a y García Cácerl, R.: Teresa de Jesús. La construcción de la santidad femenina. Madrid, Cátedra, 2015.

Alabrús Iglesias, R. M.a: «Entre el protestantismo y el catolicismo. Conversión y espiritualidad femenina: Juliana Morell», e-Spania, Revue interdisciplinaire d'études hispaniques médiévales et modernes. París, 26 février, 2017, pp. 1-15.

Lemolt Imprimeur et Libraire de sa sainteté et de la ville, 1680. 
ROSA M. ${ }^{a}$ ALABRÚS IGLESIAS

SILENCIO Y OBEDIENCIA EN EL PROYECTO EDUCATIVO DE LA CATALANA JULIANA MORELL (1594-1653)

Alabrús Iglesias, R. M.a: «Los confesores y los relatos autobiográficos de monjas en la transición del siglo Xvi al siglo Xvir: Hipólita de Rocabertí y Ana Domenge» (revista Pedralbes, en prensa).

Ahumada Batlle, E. de (ed.): Epistolaris d'Hipòlita Roís de Liori i d'Estefania de Requesens (segle XVI). Valencia, Universitat de València, 2003.

Ahumada Batlle, E. de: «Juliana Morell, una humanista catalana», Institut Nova Historia, mayo, 2010, https://www.inh.cat.

Ahumada Batlle, E. de: «La carta privada a l’època moderna: un epistolari conventual femení inèdit», Manuscrits, 29, 2011, pp. 51-64.

Baranda Leturio, N. y Marín, M. a del C.: Letras en la celda. Cultura escrita de los conventos femeninos en la España Moderna. Madrid, Ed. Iberoamericana-Vervuert, 2014.

BARón, P.: «Biografía de Julienne Morell», en La Règle de Saint Augustin traduite en français et enrichie de diverses explications et belles remarques pour servir d'instruction à toutes les personnes qui font profession de la suivre, par la R.M. Julienne Morell, religieuse de $S$. Dominique du Convent de Sainte-Praxède de la ville d'Avignon, Aviñón, Chez Laurens Lemolt Imprimeur et Libraire de sa sainteté et de la ville, 1680, pp. 235-249.

Beauchamps, M. de M.: «Abregé de la vie de la Vénerable et heureuse mémoire de la mère Julienne Morell, vierge de l'Ordre des Frères Prêcheurs et Religieuse du Monastère de Sainte-Praxède de la ville d'Avignon", en La Règle de Saint Augustin traduite en français et enrichie de diverses explications et belles remarques pour servir d'instruction à toutes les personnes qui font profession de la suivre, par la R.M. Julienne Morell, religieuse de S. Dominique du Convent de Sainte-Praxède de la ville d'Avignon. Aviñón, Chez Laurens Lemolt Imprimeur et Libraire de sa sainteté et de la ville, 1680, pp. 196-234.

Bisello, L.: Sotto il «manto» del silenzio. Storia e forme del tacere (secoli XVI-XVII). Florencia, Olschki, Sagge di Lettere italiane, 60, 2003.

EgIDo, T.s: «Santa Teresa y sus cartas, historia de los sentimientos», Hispania Sacra, vol. 67, 136, 2015, pp. 401-428.

EgIDo, T.: «Información y comunicación en el siglo xvi: las cartas de santa Teresa de Jesús», en González Martínez, R. M. a, Berrocal Gonzalo, S. y Martín de la Guardia, R. (coords.): Estudios en homenaje al profesor Celso Almuiña Fernández: Historia, periodismo y comunicación. Valladolid, Universidad de Valladolid, 2016, pp. 79-96.

Estela-Guilemont, M.: «El silencio es útil a toda persona cristiana. Considérations sur quelques silences", en Merle, Alexandra y Guillaume-Alonso, A. (dirs.): Les voies du silence dans l'Espagne des Habsbourg. París, PUPS, Université Paris-Sorbonne, 2013, pp. 23-46.

EsPONERA, A.: «San Vicente Ferrer y la misericordia», Vida sobrenatural: revista de teología mística, año 96, n. ${ }^{\circ} 706,2016$, pp. 267-270.

Esponera, A.: «Reflexiones de san Vicente Ferrer sobre la vida religiosa a las monjas dominicas de Estavayer-Le-Lac (Suiza) en 1404», Teología espiritual, vol. 51, n. ${ }^{\circ}$ 151, 2007, pp. 103-117.

FrIEDA, L.: Catalina de Médici. Una biografía. Madrid, Siglo XXI, 2005.

Ediciones Universidad de Salamanca / @థ®요 Stud. his., H. ${ }^{a}$ mod., 40, n. 1 (2018), pp. 159-183 
Ferrières, M.: «La peste, le juif et le protestant (Avignon 1628-1630)», en Audisio, G., Betrand, R., Ferrières, M. y otros (dirs.): Identités juives et chrétiennes. Provence, Presses Universitaires de Provence, pp. 167-177.

GABRIEL, F.: «Silence du crâne. Hypothèse pour une théologie du silence en images», en Merle, Alexandra y Guillaume-Alonso, A. (dirs.): Les voies du silence dans l'Espagne des Habsbourg. París, PUPS, Paris-Sorbonne, 2013, pp. 47-66.

Gassó, M. y Espargaró, A.: Aventureres de la Història: els altres noms propis de la Història de Catalunya. Barcelona, La Esfera de los Libros, 2006.

Gavastón, J.: La Regla que profesan las beatas de la Tercera Orden de Predicadores. Juan Crisóstomo Garriz, Valencia, 1621, vol. I.

HAAG, E. y E.: La France protestante ou vies des protestants qui se sont fait un nom dans l'bistoire. Depuis les premiers temps de la Réformation jusqu'à la reconnaissance du principe de la liberté des cultes par l'Assemblée Nationale. París, Bureaux de la Publication, Rue St. Dominique d'Enfer, 11, 1846, vol. I.

Hernández, B.: «Hombres de negocios y finanzas públicas en la Cataluña de Felipe II», Revista de Historia Económica, Universidad Carlos III, Madrid, año 15, n. ${ }^{\circ}$ 1, 1997.

Lamy, T.: Child Prodigy, Religious Reformer, Spiritual Writer, Ph D, Nueva York University, 1992.

Levesque, J.-D. o. p.: «Julienne Morell», Mémoire Dominicaine. Histoire Documents. Vie Dominicaine. Courants dominicains de spiritualité, n. ${ }^{\circ}$, París, Les Editions du Cerf, 1993, pp. 79-100.

Morel-Fatio, A.: «Carta de Juan Antonio Morell, dando noticias circunstanciales de su célebre hija Juliana», Revista de Archivos, bibliotecas y museos, Madrid, 1876, pp. 195-199.

Morell, J. (trad.): Precationes Aliquot celebriores e sacris Bibliis desumptae ac in studiorum gratia lingua Hebraica, Graeca E Latine in Enchiridis formulam redactae. París, Martinum Iuvenem, 1604.

Morell, J. (trad.): Traité de la vie spirituelle par Saint Vincent Ferrier. París, Denis Moreau, 1619.

Morell, J.: Exercices Spirituels sur l'éternité, avec quelques autres méditations de divers sujets et un petit Exercice préparatoire pour la Sainte Profession. Aviñón, Imprimeur de Jean Piot, Imprimeur du S. Office, 1637.

Morell, J. (trad.): La Règle de Saint Augustin traduite en français et enrichie de diverses explications et belles remarques pour servir d'instruction à toutes les personnes qui font profession de la suivre. Aviñón, Chez Laurens Lemolt Imprimeur et Libraire de sa sainteté et de la ville, 1680.

Rodríguez, A.: Ejercicio de perfección y virtudes cristianas. Parte tercera. De varios medios para alcanzar la virtud y la perfección. Barcelona, Imprenta Pablo Riera, 1861, vol. IX.

Rousset, M. J.: La Vénerable mère Julienne Morell, sa vie, sa doctrine, son institut. París, Lyon, Delhomme et Briquet, 1893.

Ediciones Universidad de Salamanca / @థ®요 Stud. his., H. ${ }^{a}$ mod., 40, n. 1 (2018), pp. 159-183 
Rousset, M. J. (ed.): CEuvres spirituelles de la V. M. Julienne Morell/Le chemin de la perfection et dix petits traités. París, Lyon, Delhomme et Briquet, 2. ${ }^{\text {ed., }} 1895$.

SouÈges, E. T. o. p.: «La vie de la Vénérable Mère Julienne Morell, professe du Monastère de Sainte- Praxède à Avignon», L'année dominicaine. Amiens, Chez Guislain Le Bel, vol. 6, 1678.

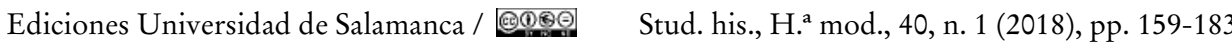

